\title{
Debate
}

\section{Even dying must be edited: further thoughts on Joan Robinson}

\author{
Stephen Curry Department of Obstetrics and \\ Gynaecology, University of Connecticut School of \\ Medicine, Farmington, Connecticut, USA
}

Arthur Zucker and Joanne Trautmann Department of Humanities, College of Medicine, The Milton S Hershey Medical Center, The Pennsylvania State University, Hershey, Pennsylvania, USA

\section{Authors' abstract}

'Foan Robinson: One Woman's Story' is a cinéma vérité style record of a woman's losing struggle against ovarian cancer. The film has been shown now twice on the American Public Television Network. It has received good notices primarily from the lay press. Yet the film depicts much that is out-of-date and much that is debatable. In general, we feel that it presents a depressing picture of the cancer patient. This was not foan Robinson's intention and her bravery only serves to highlight this picture of suffering with cancer.

We point to specific flaws in the film. We then go on to account for why many reviewers seem to have been blind to these flaws. It is suggested that criteria for good works of art, for good public health information, and for admirable personal traits were confused.

We were surprised when we read Bernard Towers' 'Report from America' (I). Professor Towers praises a televised documentary, foan Robinson: One Woman's Story ( $(\mathcal{R} R W S$ ), as the one television programme of 'real intellectual quality' which the Americans have exported to the British. We, in contrast, think Dallas far less noxious.

Professor Towers reports that when the film of a 43-year-old woman dying painfully from ovarian cancer was first shown on 21 January 1980, the audience response appeared to be 'almost uniformly positive'. But on 22 January four very frightened patients called our gynaecological oncology clinic about the programme. 'Will I have pain like Joan's?' they wanted to know. 'Will it be treated?' 'Am I being told the whole story about my cancer?'

As these reactions show, to point to 'One
Woman's Story' and hope that no further ç్nclusions beyond Joan Robinson will be drawn Pis naive at best. $\mathscr{F} R O W S$ was all too easily seen $\overline{b y}$ our anxious patients as the model for the natumal history of ovarian cancer and for the correct amd only possible doctor-patient relationship. The patients need to know (and Professor Towers_to remember) that since Joan Robinson's death, medicine has changed in major ways and, inevitabdy, so have attitudes. There are new knowledge and new modes of therapy. The use of radiation therapy and multiple surgical interventions on a patient wath uncontrolled ovarian cancer would today be highly questionable. The option for no treatment at allis seen as (more) reasonable and would have saped Joan a good deal of misery. Pain is now much less of a problem due to new and more accessible drugs. Moreover, multidisciplinary approaches are ngw common, and many cancer patients can draw on the services not only of physicians, but also of oncolgूgy nurses, social workers, dieticians, psychologists, and religious counsellors. Finally, the hospice mo $\overrightarrow{\text { ee}}-$ ment has become widely accepted. Today Jơn and her husband could arrange for her to die home, a goal they found impossible.

There are equally disturbing issues concerning the doctor-patient relationship. Joan does not feel that she gets adequate time from her physician a d is made to feel that she gets only what she deservis. No wonder, then, that she questions the forgrightness of her physician. Her fears are entirely appropriate as we see when we are privy to Bis lying to Joan about her tumour having melted away. Later the physician makes it plain that he wants Joan to have a mastectomy. And when she triesnto wrest more information from him, he says he has to leave. Even the spatial element of the relationsisup is awry. Often one sees a picture of a patient in bed and a doctor at the door. This is surely distare personified.

Some patients and physicians may do well on thisis sort of relationship. But the cancer patient should not be led to expect it, and, more important, shoutd not have to tolerate such a relationship if it exists. Nothing in $\mathcal{F R O W S}$, or in the panel's commems on the film which followed after its initial showing alleviates the fear that this is the way things are and the way they must be. Nowhere does one get the impression that having cancer does not nece्ssarily force one into a cold and impersonal worki 
Nowhere does one sense that the emphasis in many institutions today is on close, warm support. We know that patients can have both cancer and dignity. JR's celluloid legacy did not reflect this.

Why then was $\mathcal{H} R O W S$ so well received? In part, there was a lack of proper focus in the responses; in part, a conceptual error. Many of the reviewers dealt with the uniqueness of the documentary - the honesty of the characters and the good, strong will of a doomed JR. Much was made of the crew's becoming part of the environment. Praising the project because the film is unique is a mistake. It confuses the work with its use. Praising the project because of Joan's admittedly admirable character is also an obvious mistake. The focus of reviewers should have been on the merit of the project: that is, what is involved in showing this film on public television when a proportion of the audience will have a deep emotional stake in the subject matter, and on related criteria for judging the work. In what follows, we offer a basis for what we deem a more appropriate response to the film.

\section{A work of art?}

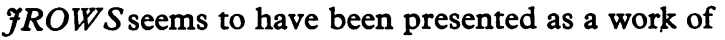
art. Works of art can be ambiguous. That quality may even be their strength. But $\mathscr{F} O W S$-on-public $\mathrm{TV}$ is an entity different from $\mathcal{F} O W S$. $\mathcal{F} R O W S$ on-public TV is, like it or not, a piece of public health education and as such requires criteria slightly different from the usual aesthetic criteria in order to judge it properly. Four questions often used for evaluating works in the health education genre are: is the work intelligible? is it accurate? is it current? and what is its applicability (that is, the generalisability of what is seen or heard)?

We suggest that $f R O W S$-on-public TV can answer 'yes' to intelligibility and, because $\mathfrak{F} R O W S$ was cinéma vérité, a trivial 'yes' to a specious kind of accuracy. It can give a qualified 'yes' to currency. 'Yes' because it was made as Joan was living through some of the events captured. 'No' because Joan was not present for some of the events. 'No' again because the events took place in what, in the speeded-up history of medicine, has become the distant past. On generalisability, $\mathcal{F} R O W S$-on-public TV creates a muddle. All works of art have some degree of universality and some degree of uniqueness. The universality is, however, irrelevant to the generalisability required of public health education. fROWS's uniqueness (due to its being cinéma vérité) forces a 'no' answer to generalisability in the sense important for public health education.

The problem is that $\mathcal{F} R O W S$-on-public TV creates, ipso facto, apparent affirmative answers to the four questions. After all, why else would it be shown on a prestigious public network? But unless the audience is aware, or is made aware, that a work of art has been reworked and allowed to masquerade as information, then it is likely that the uniqueness of the work of art (what happened to Joan in all its subtle texture) will be mistaken for the generalisability of the public information (Joan representing today's ovarian cancer patient). And that leaves the audience with misunderstanding and apprehension.

Now what could have been done by the film makers in order to serve JR's goals and those of public television? We think there is one major answer: the film requires much more focused editing. As it stands, in its three-hour, badly edited state, it is, in the first place, far too long. Furthermore, there is little interpretation, either in the form of a voice-over commentator (which, of course, would have assaulted the viewers' sense of being there), or in the form of using footage to point the way subtly to the significance of Joan's suffering for her and those close to her. Bernard Towers has called the film 'cinéma vérité of the truest kind ... that makes one realise again how truly human the film medium can become.' But we think $\mathcal{H} R O W S$ is no more truthful simply because it records more details than the next film and because it does so in a seemingly nonjudgemental way. Proper editing would have been, we believe, much more truthful, and, considering the appalling effect the film had on some members of the emotionally drained audience, more truly human as well.

\section{The vagueness of the concept of 'truth'}

Indeed, Professor Towers trades on the vagueness of the concept of 'truth.' 'Cinéma vérité of the truest kind' can be a mere description of the way the film was made and edited. 'Truly human' however, leaves the impression that the film is morally uplifting and compassionate. But surely, the best cinéma vérité need not be morally uplifting (eg true cinéma vérité of a 12-year-old girl being raped and killed), nor need a compassionate and uplifting film be cinéma vérité.

Moreover, 'true' in terms of corresponding to present reality, an important sense for public health information, is not necessarily captured by showing what truly happened to Joan Io years ago; unless, of course, proper editing is applied, which destroys the 'vérité'. In a way though, this is the point overlooked by Towers. fROWS is a mere list of events, and while cinéma vérité of the truest kind, is almost certainly less true, in precisely the sense relevant to public education. To use a distinction drawn from statistics, $\mathfrak{F} R O W S$ has precision but remains nonetheless, inaccurate.

The panel of professional experts which commented on the film after its showing, and which could have provided some of the editorial comment we need without in any way damaging the artistic intent of the film, did not achieve these ends. 
Perhaps the 30 minutes allotted to the panel was not enough time in which to redirect interpretation. We can only hope that the books and study-guides, of whose existence Bernard Towers informs us, will fill in the powerfully dangerous gaps left inevitably by the showing of $\mathcal{H R O W S}$ in an educational context. Student viewers of the film might then see the differences between what was, what is, and what ought to be.

Joan Robinson wanted to make this film so that others might benefit from her experiences. Sadly, the public television version of her life and dying, poorly edited and poorly interpreted afterwards, conflicts with Joan's wishes.

\section{Reference}

(I) Towers, B. Report from America: A television triumph about death and dying. Fournal of medical ethics 1980; 6: 1OI-IO2.

\section{Response}

Bernard Towers University of California, Los Angeles: American Correspondent, fournal of medical ethics

All the criticisms voiced by your correspondents were vigorously pursued during the weeks preceding the broadcast. Opposition to public screening, especially from the politically powerful American Cancer Society ( $A C S$ ), a private fund-raising organisation, was intense. In the result, and despite all efforts by what I called 'the cancer industry' to persuade the Public Broadcasting System (PBS) to drop its plans, all stations except one did broadcast the film. Moreover, in view of the general response, the broadcast was repeated nationwide on 15 September 1980 to renewed critical acclaim.

Many patients and friends of patients were prompted to use the telephone hot-lines. There is something skewed about the sample of four frightened patients reported by your correspondents. However, they at least were prompted to call and to create for themselves an opportunity for open and honest dialogue with their medical advisors. Therapy and prognosis for ovarian cancer have not changed all that much, in fact; the incidence is increasing, and patients have a right to ask frank questions. Some may indeed do better with only supportive psychological therapy. Joan Robinson, in contrast, looked to modern technological medicine for active intervention with a view to cure almost to the end. It is not surprising that the ACS was defensive about the results here portrayed with total honesty.

Two governmental agencies, the National Endowment for the Humanities (NEH) and the National Cancer Institute (NCI) supported the film throughout the controversy. The NCI has published an analysis of 1526 letters received in response to the broadcast. (I) Only three (0.19 pes cent) were critical, and two of those were unsigned More than 30 per cent were from cancer patients; or relatives or friends of patients, and more than 12 per cent were from health professionals. Earlies figures from the same office are quoted by Erie Robinson in an extensive review article recently published by the National Association of Educaథ tional Broadcasters. (2)

Controversial topics, and controversial treatment of such topics, tend naturally to generate discussion $\vec{\ominus}$ especially perhaps amongst those of us who are members of the Society for Health and Humaw Values. This body supported the film, and its president co-ordinated a series of five recorded $\bar{D}$ panel-discussions on some of the sensitive issues

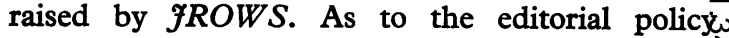
criticised by your correspondents, a policy which deliberately eschewed the kind of voice-overs and other tricks of the TV trade that they advocate, it should be realised that this was precisely how Joan wanted her story to be told. The benefits, in my? view, far outweigh the drawbacks. Far from detracting from the quality of the production thiso method of editing positively enhanced it. Audiences are sceptical of most documentary films precisely because they know that the 'message' is determined and packaged by the producer-editor. Joan wantec her story told the way she lived it, the way it was 'warts and all'. Her husband and her producer $\mathbb{D}$ friend honoured her wishes.

The additional teaching-modules to which referred in my article have now been released bye Time-Life Video of New York. The series iș entitled 'Coping With Serious Illness'. Six thirty minute presentations are introduced by Meryb Streep, whose sensitive playing in Kramer vs: Kramer won her an Oscar.

I am currently teaching an undergraduate seminaro entitled 'Approaches to Death'. The students have gained, through $\mathcal{F R O W S}$ and all the teaching materials to which the film has given rise, much insight into and compassion for all those involved? in coping with terminal illness. They do notn generalise, as my critics suggest, from what was ${ }^{\circ}$ called quite precisely 'One Woman's Story'. Had it been editorialised in the way suggested by Curry $N$ Zucker and Trautmann, then, no matter howO sensitively done, the film would not have been theo triumph that I reported it to be.

\section{References}

(I) Office of Cancer Communications Memorandum,, $\mathbb{D}$ Sept 2: (typescript 29 pp. including 6 tables), $\overrightarrow{\mathbb{D}}$ National Cancer Institute: National Institutes of $\varrho$ Health, I980.

(2) Robinson E. Joan Robinson: One woman's story .8 The aftermath. Public telecommunications reviewo 1980; 8(4): 5-13. 